\title{
Effectiveness and Technical Considerations of Solitaire Platinum 4×40 mm Stent Retriever in Mechanical Throm- bectomy with Solumbra Technique
}

\author{
Ho Jun Yi, ${ }^{1,2}$ Jae Hoon Sung, ${ }^{1}$ Dong Hoon Lee, 'Seung Yoon Song' \\ Department of Neurosurgery, St. Vincent's Hospital, College of Medicine, The Catholic University of Korea, Suwon, Korea \\ Department of Neurosurgery, ${ }^{2}$ Hangang Sacred Heart Hospital, College of Medicine, Hallym University, Seoul, Korea
}

Objective : The Solitaire Platinum $4 \times 40 \mathrm{~mm}$ stent retriever contains radiopaque markers with a long length. We evaluated the effect of Solitaire Platinum $4 \times 40 \mathrm{~mm}$ stent retriever in Solumbra technique thrombectomy, and compared it with shorter Solitaire stent retrievers.

Methods : A total of 70 patients who underwent Solumbra technique thrombectomy with equal diameter $(4 \mathrm{~mm})$ and different length $(40$ vs. $20 \mathrm{~mm}$ ) Solitaire stent retrievers were divided into two groups : the Solitaire Platinum $4 \times 40 \mathrm{~mm}$ stent $(4 \times 40)$ group and the Solitaire FR $4 \times 20 \mathrm{~mm}$ stent or Solitaire Platinum $4 \times 20 \mathrm{~mm}$ stent $(4 \times 20)$ group. The clinical outcomes, Thrombolysis in Cerebral Infarction score, the first pass reperfusion status, and complications were evaluated and compared between the two groups. Multivariate analysis was performed to evaluate the predictive factors for reperfusion and complete reperfusion from the first pass.

Results : Higher first-pass reperfusion and complete reperfusion were achieved in the $4 \times 40$ group (68.0\% and $48.0 \%)$ than in the $4 \times 20$ group ( $46.7 \%$ and $33.3 \% ; p=0.004$ and 0.007 , respectively). In multivariate analysis, radiopaque device and longer stent retriever were correlated with first-pass reperfusion ( $p=0.014$ and 0.008 , respectively) and first-pass complete reperfusion $(p=0.022$ and 0.012 , respectively).

Conclusion : Our study demonstrated the usefulness of the Solitaire Platinum $4 \times 40 \mathrm{~mm}$ stent retriever, which led to higher firstpass reperfusion and complete reperfusion rates than the Solitaire FR $4 \times 20 \mathrm{~mm}$ stent or the Solitaire Platinum $4 \times 20 \mathrm{~mm}$ stent, especially in Solumbra technique thrombectomy.

Key Words : Angiography $\cdot$ Reperfusion $\cdot$ Stents $\cdot$ Stroke $\cdot$ Thrombectomy.

\section{INTRODUCTION}

Mechanical thrombectomy (MT) is the primary modality for the treatment of acute ischemic stroke (AIS) caused by large artery occlusion (LAO). In addition, the MT technique continues to evolve in terms of its effectiveness and diversity. Initially, the effectiveness of stent retriever techniques was demonstrated via several randomized controlled trials and

- Received : February 21, 2020 •Revised : March 30, 2020 •Accepted : April 1, 2020

- Address for reprints : Jae Hoon Sung

Department of Neurosurgery, St. Vincent's Hospital, College of Medicine, The Catholic University of Korea, 93 Jungbu-daero, Paldal-gu, Suwon 16247, Korea Tel : +82-31-249-8985, Fax : +82-31-2649-7020, E-mail : jaehoonsung@gmail.com, ORCID : https://orcid.org/0000-0003-3738-6413 
meta-analyses, and the usefulness of contact aspiration technique was shown in several studies ${ }^{2,4,5,9,10,17,20,29,30)}$. In addition, a number of studies demonstrated that the chance of first-pass reperfusion was increased in Solumbra technique thrombectomy (stent retriever with simultaneous aspiration) ${ }^{8,16,21,22)}$.

Along with the evolution of MT techniques, devices for thrombectomy have also developed. The Solitaire AB stent (ev3; Covidien, Irvine, CA, USA) was the first stent-retriever device used in MT, and was developed further into the Solitaire flow restoration (FR) device and subsequently to the Solitaire 2 revascularization device. Solitaire is a nitinol stent retriever with laser-cut, attached to a push-wire with a closedcell scaffolding design ${ }^{27,28)}$. However, the Solitaire FR stent retriever had a major disadvantage of poor visualization. The next generation Solitaire stent retriever, the Solitaire Platinum (Medtronic, Dublin, Ireland) has radiopaque platinum markers, which are spaced $10 \mathrm{~mm}$ apart. The use of a radiopaque device is known to be associated with first-pass reperfu$\operatorname{sion}^{12,18)}$. In addition to the characteristics of the stent retriever, the size of the stent may affect the outcomes of MT. The appropriate stent diameter is disputed, and several reports suggested conflictingly, that a stent with a larger or smaller diameter was better ${ }^{13,31,33)}$. However, in terms of stent length rather than diameter, Haussen et al. ${ }^{12)}$ reported that longer stent retrievers enhance thrombectomy performance, probably due to the larger device-thrombus interaction area and smaller chances of missing the target site.

For these reasons, the authors used Solitaire Platinum $4 \times 40$ $\mathrm{mm}$ stent retriever with a Solumbra technique. Therefore, the purpose of our study was to assess the potential benefits of Solitaire Platinum $4 \times 40 \mathrm{~mm}$ stent retriever with its radiopacity and long length, and compared it with other Solitaire stent retrievers, especially in patients who underwent MT with Solumbra technique. In addition, the technical considerations involved in Solumbra technique thrombectomy with Solitaire Platinum $4 \times 40 \mathrm{~mm}$ stent retriever are also discussed.

\section{MATERIALS AND METHODS}

\section{Study population}

This retrospective study with prospectively collected data was approved by the Local Institutional Review Board (IRB No. VC17RESI0048) of each participating center. The data of patients with LAO who underwent Solumbra technique thrombectomies with a Solitaire stent retriever of equal diameter (4 mm) between January 2018 and July 2019 were obtained from each institution's stroke database and evaluated. All of the procedures were performed by two experienced neuro-interventionalists at two centers. A total of 70 patients were identified for enrollment. These patients were dichotomized into : 1) a $4 \times 40$ group using $4 \times 40 \mathrm{~mm}$ Solitaire stent retrievers (Solitaire Platinum $4 \times 40 \mathrm{~mm}$ stent retriever) and 2) a $4 \times 20$ group using $4 \times 20 \mathrm{~mm}$ Solitaire stent retrievers (Solitaire FR $4 \times 20 \mathrm{~mm}$ or Solitaire Platinum $4 \times 20 \mathrm{~mm}$ stent retrievers). Prior to thrombectomy, intravenous tissue plasminogen activator (IV t-PA, alteplase) was administered to patients within 4.5 hours after stroke onset at a maximum dose of $0.9 \mathrm{mg} / \mathrm{kg}$ in accordance with the European Cooperative Acute Stroke Study (ECASS) III trial ${ }^{11)}$. The inclusion criteria were as follows : 1) occlusion of the distal intracranial carotid artery (ICA), middle cerebral artery (MCA, M1, or M2), or posterior circulation (vertebral artery, or basilar artery) established by computed tomography angiography (CTA); 2) neurologic deficits; and 3) Solumbra technique thrombectomy with $4 \mathrm{~mm}$ Solitaire stent retriever. The exclusion criteria were : 1) the detection of hemorrhage on the initial CT scan; 2) presence of a large ischemic core with an Alberta Stroke Program Early CT Score (ASPECTS) $\leq 6 ; 3$ ) MT with a simple stent retriever or the contact aspiration technique. and (4) Solumbra technique thrombectomy with a stent retriever other than a $4 \mathrm{~mm}$ Solitaire stent retriever, such as a Solitaire FR $6 \times$ $30 \mathrm{~mm}$, a Solitaire Platinum $6 \times 40 \mathrm{~mm}$, a Trevo XP Provue (Stryker Neurovascular, Fremont, CA, USA), Eric (MicroVention Terumo, Tustin, CA, USA), or Revive (Codman Neurovascular, San Jose, CA, USA) devices. All patients underwent CT immediately after the intervention to evaluate hemorrhage. In addition, vessel status and hemorrhage were evaluated by CTA 24 hours after MT. Hemorrhagic transformation of the infarct and vessel status was confirmed by magnetic resonance angiography (MRA) with susceptibility-weighted imaging on day 7 after MT.

\section{Device selection and Solumbra technique}

Solumbra technique thrombectomy with a $4 \mathrm{~mm}$ Solitaire stent retriever was performed in patients with AIS caused by LAO. All of the MT procedures were performed using the Solumbra technique, entailing thrombus retraction with a stent 
retriever, such as the Solitaire FR $4 \times 20 \mathrm{~mm}$ (ev3; Covidien) or the Solitaire Platinum $4 \times 20 \mathrm{~mm}$ or $4 \times 40 \mathrm{~mm}$ (Medtronic) and simultaneous aspiration with a 5 Fr SOFIA (Sofia 5; MicroVention-Terumo, Tustin, CA, USA) or a 6 Fr AXS Catalyst 6 (CAT6; Stryker Neurovascular, Mountain View, CA, USA). In almost cases, an 8 Fr balloon-guiding catheter (BGC) (FlowGate2 [FG2]; Stryker Neurovascular, Fremont) was ap- plied. An illustration of MT with the Solumbra technique is shown in (Fig. 1). Under consciousness sedation, an 8 Fr FG2 BGC was placed in the proximal ICA. A microcatheter (Excelsior XT-18; Stryker Neurovascular, Fremont) with a microwire was advanced as distally as possible from the occlusion site, and the aspiration catheter was approached close to the occlusion site, followed by deployment of the stent retriever in the
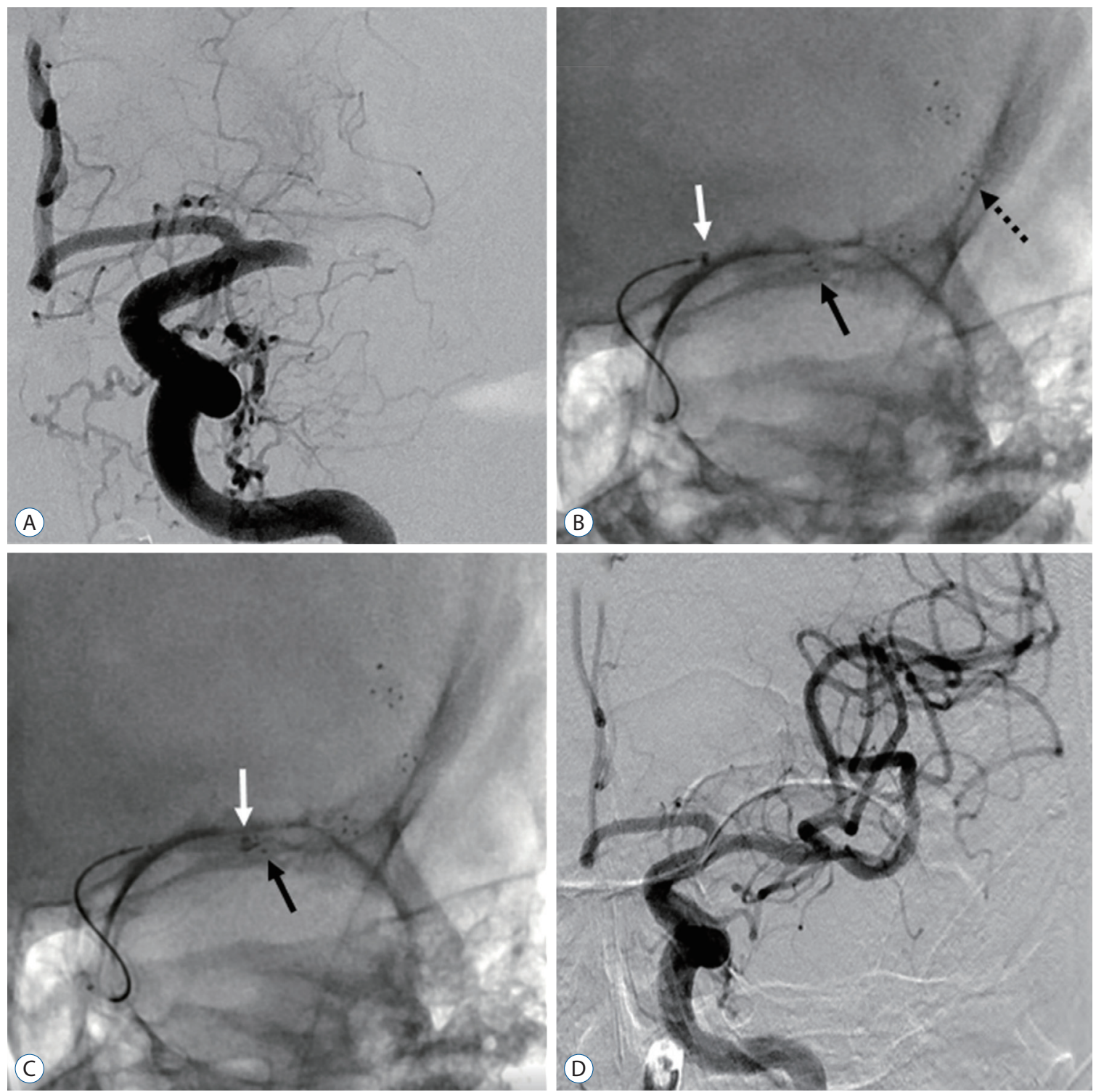

Fig. 1. Solumbra technique thrombectomy with a Solitaire platinum $4 \times 40 \mathrm{~mm}$ stent retriever. A : Initial angiography revealed left M1 occlusion. B : A non-subtracted image showed a deployed Solitaire platinum $4 \times 40 \mathrm{~mm}$ stent retriever (black arrow : the proximal end of the working device; black dotted arrow : the distal end of the working device) and a 6 French Catalyst (CAT6) aspiration catheter (white arrow : distal tip of the aspiration catheter). C : Using a weak pull of the Solitaire platinum $4 \times 40 \mathrm{~mm}$ stent retriever, the distal tip of the CAT6 aspiration catheter is moved to the proximal end of the working length of the stent retriever. To contact the thrombus, the distal tip of the CAT6 should be placed just proximal to the thrombus (black arrow : the proximal end of the working length of the stent; white arrow : distal tip of the aspiration catheter). D : After retrieval of the Solitaire platinum $4 \times 40$ $\mathrm{mm}$ and CAT6 with simultaneous aspiration, angiography revealed the complete reperfusion status of the left M1. 
Usefulness of the Solitaire Platinum $\mathbf{4 \times 4 0} \mid \mathrm{Yi} \mathrm{HJ}$, et al.

distal portion of the occlusion site. After the 3 to 5 minutes of waiting after stent deployment to promote stent clot integra$\operatorname{tion}^{32)}$, the aspiration catheter with suction and the stent retriever were slowly removed as a single unit. At this time, a dual aspiration technique was used at the BGC with manual aspiration $^{15}$.

\section{Multivariable factors and outcome and compli- cations}

Multivariable factors including patient sex, age, risk factors, prior stroke or transient ischemic attack (TIA), history of previous anti-platelet or anti-coagulant use, ASPECTS score, application of IV t-PA, stroke etiology by Trial of ORG 10172 in Acute Stroke Treatment (TOAST) classification ${ }^{1)}$, site of the arterial occlusion, and procedure time (time from groin puncture to reperfusion) were reviewed. All patients underwent clinical assessment using the National Institutes of Health Stroke Scale (NIHSS) (range, 0-42; with higher scores indicating more severe neurologic deficit) and modified Rankin Scale (mRS) scores at 3 months (a favorable clinical outcome was defined as $m R S \leq 2)$. The radiologic results were evaluated according to the thrombolysis in cerebral infarction (TICI) grading system, successful recanalization (TICI grade of $2 \mathrm{~b}$ or 3 ), first-pass reperfusion (modified TICI, mTICI 2b or 3 with the first pass), and first-pass complete reperfusion (mTICI 3 with the first pass). Various complications, such as post-thrombectomy hemorrhage at 24 hours, symptom-related hemorrhage at 24 hours, vessel perforation, arterial dissection, distal emboli, hemorrhagic transformation of the infarct on MRA 7 days after MT, and 3-month mortality were reviewed. Post-thrombectomy hemorrhage at 24 hours was defined as the occurrence of intracerebral hemorrhage or subarachnoid hemorrhage on a CTA scan obtained 24 hours after the procedure. All multimodal factors and clinical data were analyzed by all authors.

\section{Statistical analyses}

All data were analyzed using Stata Statistical Software, release 15 (Stata, College Station, TX, USA). Between-group comparisons were calculated using Student's t-test/MannWhitney U test or chi-squared test/Fisher's exact test. Multivariate logistic regression analyses were performed for variables with $<0.2$ level of significance in univariate analysis. Two-tailed $p$-value of $\leq 0.05$ were considered to indicate significant difference.
Table 1. Baseline characteristics of patients in Solumbra technique thrombectomy, according to the length of Solitaire stent retriever

\begin{tabular}{|c|c|c|c|}
\hline Variable & $\begin{array}{c}4 \times 40 \\
\text { (25 patients) }\end{array}$ & $\begin{array}{c}4 \times 20 \\
\text { (45 patients) }\end{array}$ & $p$-value* \\
\hline \multicolumn{4}{|l|}{ Dermographic } \\
\hline Sex, male & $14(56.0)$ & $27(60.0)$ & 0.601 \\
\hline Age (years) & $72.0 \pm 12.7$ & $69.0 \pm 13.1$ & 0.449 \\
\hline HTN & $15(60.0)$ & $25(55.6)$ & 0.552 \\
\hline $\mathrm{DM}$ & $5(20.0)$ & $10(22.2)$ & 0.680 \\
\hline Af & $8(32.0)$ & $12(26.7)$ & 0.346 \\
\hline$C A D$ & $5(20.0)$ & $9(20.0)$ & 0.889 \\
\hline Dyslipidemia & $7(28.0)$ & $16(35.6)$ & 0.465 \\
\hline Smoking & $5(20.0)$ & $13(28.9)$ & 0.263 \\
\hline Prior stroke or TIA & $4(16.0)$ & $7(15.6)$ & 0.793 \\
\hline Previous anti-platelet use & $6(24.0)$ & $9(20.0)$ & 0.571 \\
\hline Previous anti-coagulant use & $3(12.0)$ & $4(8.9)$ & 0.466 \\
\hline $\begin{array}{l}\text { Occlusions in the left } \\
\text { hemisphere }\end{array}$ & $14(56.0)$ & $24(53.3)$ & 0.702 \\
\hline IV t-PA & $8(32.0)$ & $18(40.0)$ & 0.109 \\
\hline Initial NIHSS & $10(2-18)$ & $8(2-18)$ & 0.127 \\
\hline ASPECTS score & $9(6-10)$ & $9(6-10)$ & 0.924 \\
\hline \multicolumn{4}{|l|}{ Etiology of stroke } \\
\hline Cardio-embolic & $10(40.0)$ & $22(48.9)$ & 0.297 \\
\hline Atherosclerosis & $7(28.0)$ & $10(22.2)$ & 0.382 \\
\hline Dissection & $1(4.0)$ & $1(2.2)$ & 0.307 \\
\hline Other or undetermined & $7(28.0)$ & $12(26.7)$ & 0.693 \\
\hline \multicolumn{4}{|l|}{ Site of arterial occlusion } \\
\hline MCA & $13(52.0)$ & $27(60.0)$ & 0.419 \\
\hline Distal ICA & $10(40.0)$ & $13(28.9)$ & 0.310 \\
\hline Posterior circulation & $2(8.0)$ & $5(11.1)$ & 0.507 \\
\hline \multicolumn{4}{|l|}{ Procedure detail } \\
\hline Procedure time (minutes) & $34(14-82)$ & $46(15-91)$ & 0.247 \\
\hline Use of BGC & $24(96.0)$ & $42(93.3)$ & 0.776 \\
\hline Aspiration catheter, CAT6:Sofia5 & $21: 4$ & $33: 12$ & 0.186 \\
\hline Radiopaque stent retriever & $25(100.0)$ & $20(44.4)$ & $0.001^{\dagger}$ \\
\hline
\end{tabular}

Values are presented as mean \pm standard deviation, median (interquartile range), or number (\%). ${ }^{*} p$-values are calculated by chi-square test or Fisher's exact test and Mann-Whitney $U$ test or Student's t-test. ${ }^{\dagger}$ Statistically significant. $4 \times 40$ : Solitaire Platinum $4 \times 40 \mathrm{~mm}$ stent retriever, $4 \times 20$ : Solitaire 2 FR $4 \times 20 \mathrm{~mm}$ stent retriever + Solitaire Platinum $4 \times 20 \mathrm{~mm}$ stent retriever, HTN : hypertension, DM : diabetes mellitus, Af : atrial fibrillation, CAD : coronary artery disease, TIA : transient ischemic attack, IV t-PA : intravenous tissue-plasminogen activator, NIHSS : National Institutes of Health Stroke Scale, ASPECT : Alberta Stroke Program Early CT, MCA : middle cerebral artery, ICA : internal carotid artery, BGC : balloon guide catheter, CAT6: 6 Fr Catalyst, Sofia5 : 5 Fr Sofia 


\section{RESULTS}

\section{Baseline characteristics and procedure detail}

Twenty-five patients (14 males, 56.0\%) were treated via Solumbra technique thrombectomy with $4 \times 40 \mathrm{~mm}$ Solitaire Platinum stent retriever ( $4 \times 40$ group), and 45 (27 males, $60.0 \%$ ) underwent Solumbra technique thrombectomies with $4 \times 20 \mathrm{~mm}$ Solitaire stent retrievers ( $4 \times 20$ group). The mean age of the patients in the $4 \times 40$ group was 72 years (standard deviation [SD], 12.7) and that of the $4 \times 20$ group was 69 years (SD, 13.1). There were no significant differences in multiple risk factors such as hypertension, diabetes mellitus, atrial fibrillation, coronary artery disease, dyslipidemia, smoking, history of prior stroke or TIA, history of anti-platelet use, previous anti-coagulation use, the proportion of left hemisphere strokes, and the rate of IV t-PA application, between $4 \times 40$ and

Table 2. Outcomes and complications of patients in Solumbra technique thrombectomy, according to the length of Solitaire stent retriever

\begin{tabular}{|c|c|c|c|}
\hline & $\begin{array}{c}4 \times 40 \\
\text { (25 patients) }\end{array}$ & $\begin{array}{c}4 \times 20 \\
(45 \text { patients) }\end{array}$ & $p$-value* \\
\hline \multicolumn{4}{|l|}{ Outcome } \\
\hline Successful recanalization & $24(96.0)$ & $43(95.6)$ & 0.842 \\
\hline First-pass reperfusion & $17(68.0)$ & $21(46.7)$ & $0.004^{\dagger}$ \\
\hline $\begin{array}{l}\text { First-pass complete } \\
\text { reperfusion }\end{array}$ & $12(48.0)$ & $15(33.3)$ & $0.007^{\dagger}$ \\
\hline Favorable 3 months mRS & $14(56.0)$ & $23(51.1)$ & 0.592 \\
\hline \multicolumn{4}{|l|}{ Complication } \\
\hline $\begin{array}{l}\text { Post thrombectomy } \\
\text { hemorrhage }\end{array}$ & $2(8.0)$ & $4(8.9)$ & 0.627 \\
\hline Symptomatic hemorrhage & $1(4.0)$ & $2(4.4)$ & 0.793 \\
\hline Vessel perforation & $0(0.0)$ & $0(0.0)$ & 1.000 \\
\hline Arterial dissection & $0(0.0)$ & $0(0.0)$ & 1.000 \\
\hline Distal emboli & $2(8.0)$ & $4(8.9)$ & 0.679 \\
\hline $\begin{array}{l}\text { Hemorrhagic } \\
\text { transformation of infarct }\end{array}$ & $4(16.0)$ & $9(20.0)$ & 0.391 \\
\hline 3 months mortality & $2(8.0)$ & $4(8.9)$ & 0.497 \\
\hline
\end{tabular}

Values are presented as number (\%). * $p$-values are calculated by chisquare test or Fisher's exact test and Mann-Whitney $U$ test or Student's t-test. 'Statistically significant. $4 \times 40$ : Solitaire Platinum $4 \times 40 \mathrm{~mm}$ stent retriever, $4 \times 20$ : Solitaire 2 FR $4 \times 20 \mathrm{~mm}$ stent retriever + Solitaire Platinum $4 \times 20 \mathrm{~mm}$ stent retriever, Successful recanalization : thrombolysis in cerebral infarction 2b or 3, mRS : modified Rankin Scale, Favorable mRS : 90 days $m R S \leq 2$, First-pass reperfusion : modified thrombolysis in cerebral infarction $2 \mathrm{~b}$ or 3 with the first pass, First-pass complete reperfusion : modified thrombolysis in cerebral infarction 3 with the first pass
$4 \times 20$ groups. The median initial NIHSS value, and ASPECTS scores were 10 and 9 , respectively, in the $4 \times 40$ group and 8 and 9 , respectively, in the $4 \times 20$ group, without significant difference. There was no significant difference in stroke etiology between the two groups. The site of arterial occlusion in each group was as follows ( $4 \times 40$ group : $4 \times 20$ group) : MCA, 13 : 27; distal ICA, $10: 13$; and posterior circulation, $2: 5$. In terms of procedure, there were no statistically significant differences in procedure time and the rate of BGC application between the two groups ( $p=0.247$ and 0.776 , respectively). The distribution ratio of the two-aspiration catheters (CAT6: Sofia5) was $21: 4$ in the $4 \times 40$ group, and $33: 12$ in the $4 \times 20$ group $(p=0.186)$. Radiopaque devices were significantly more common in the $4 \times 40$ group ( $p=0.001$ ), suggesting that 25 non-radiopaque Solitaire FR $4 \times 20 \mathrm{~mm}$ stents were included in the 4 $\times 20$ group (Table 1 ).

\section{Outcomes and complications}

No statistically significant difference was found in the rate of successful recanalization, between the two groups ( $4 \times 40$ group : $4 \times 20$ group, $96.0 \%: 95.6 \%$; $p=0.842$ ). However, the

Table 3. Multivariable regression for first-pass reperfusion and first-pass $\mathrm{TICl} 3$ reperfusion

\begin{tabular}{|c|c|c|c|}
\hline & OR & $95 \% \mathrm{Cl}$ & $p$-value* \\
\hline \multicolumn{4}{|l|}{ First-pass reperfusion } \\
\hline Initial NIHSS & 2.95 & $0.61-4.38$ & 0.442 \\
\hline IV t-PA & 0.97 & $0.58-2.26$ & 0.367 \\
\hline CAT6 Aspiration catheter & 1.86 & $0.78-3.14$ & 0.172 \\
\hline Radiopaque stent retriever & 2.08 & $1.22-3.84$ & $0.014^{\dagger}$ \\
\hline $\begin{array}{l}\text { Long stent retriever (Platinum } \\
\qquad 4 \times 40 \mathrm{~mm} \text { ) }\end{array}$ & 2.81 & $1.34-4.10$ & $0.008^{\dagger}$ \\
\hline \multicolumn{4}{|l|}{ First-pass complete reperfusion } \\
\hline Initial NIHSS & 2.72 & $0.58-4.46$ & 0.407 \\
\hline IV t-PA & 0.82 & $0.66-3.08$ & 0.266 \\
\hline CAT6 Aspiration catheter & 2.06 & $0.82-3.90$ & 0.312 \\
\hline Radiopaque stent retriever & 1.88 & $1.20-3.12$ & $0.022^{\dagger}$ \\
\hline $\begin{array}{l}\text { Long stent retriever (Platinum } \\
4 \times 40 \mathrm{~mm} \text { ) }\end{array}$ & 2.12 & $1.48-3.76$ & $0.012^{\dagger}$ \\
\hline
\end{tabular}

${ }^{*} p$-values are calculated by multivariate logistic regression analysis. ${ }^{\dagger}$ Statistically significant. $\mathrm{TICl}$ : thrombolysis in cerebral infarction, $\mathrm{OR}$ : odds ratio, $\mathrm{Cl}$ : confidence interval, First-pass reperfusion : modified $\mathrm{TICl}$ $2 \mathrm{~b}$ or 3 with the first pass, NIHSS : National Institutes of Health Stroke Scale, IV t-PA : intravenous tissue-plasminogen activator, CAT6 : 6 French Catalyst, First-pass complete reperfusion : modified $\mathrm{TICI} 3$ with the first pass 
proportion of first-pass reperfusions and first-pass complete reperfusions was significantly higher in the $4 \times 40$ group, compared to the $4 \times 20$ group ( $68.0 \%$ vs. $46.7 \%$ and $48.0 \%$ vs. $33.3 \%, p=0.004$ and 0.007 , respectively). There were no significant differences in complications, between the two groups (Table 2).

\section{Predictors of reperfusion and full reperfusion with first pass}

In multivariate logistic regression analysis, the use of radiopaque Solitaire stent retriever (odds ratio [OR], 2.08; 95\% confidence interval [CI], 1.22-3.84; $p=0.014$ ), and longer Solitaire Platinum $4 \times 40 \mathrm{~mm}$ stent retrievers (OR, 2.81; 95\% CI, $1.34-4.10 ; p=0.008)$ were correlated with first-pass reperfusion. In addition, multivariate logistic regression analysis for first-pass complete reperfusion indicated that the use of radiopaque devices (OR, 1.88; 95\% CI, $1.20-3.12 ; p=0.022)$ and longer Solitaire Platinum $4 \times 40 \mathrm{~mm}$ stents (OR, 2.12; 95\% CI, $1.48-3.76 ; p=0.012$ ) were independent predictors (Table 3 ).

\section{DISCUSSION}

Currently, the development of various thrombectomy tech- niques has enhanced the clinical and radiologic outcomes of patients with $\mathrm{LAO}^{6,7,19)}$. Recent advances in MT pursuit the first pass effect (first-pass reperfusion or first-pass complete reperfusion), beyond simple successful recanalization ${ }^{25)}$. The importance of the first-pass effect has been reported in various studies, where it was associated with a significantly higher chance of favorable clinical outcomes with the retrieval of the entire thrombus as a single mass on the first attempt $\mathrm{t}^{23,24,34)}$. Fewer stent passages reduced the risk of procedure-related complications, such as parenchymal hematoma and other vessel damage ${ }^{3)}$. Therefore, the utility of the Solumbra technique contributes to reperfusion or complete reperfusion from the first pass ${ }^{14,21,25)}$. Based on these studies, the authors used Solumbra technique for MT in most cases. In addition to thrombectomy techniques, the device may be considered a factor affecting the outcomes of MT. There are several controversies related to the selective advantages of stent retrievers with an appropriate diameter. However, recent studies have suggested that stent retrievers with longer lengths and radiopaque characteristics yield better outcomes ${ }^{12,13,18,31)}$. In our study, longer and radiopaque stent retrievers were found to increase the first-pass effect. The reperfusion and complete reperfusion rates with first pass were significantly higher in the group with $4 \times 40 \mathrm{~mm}$ long stent retrievers than in those with $4 \times 20 \mathrm{~mm}$
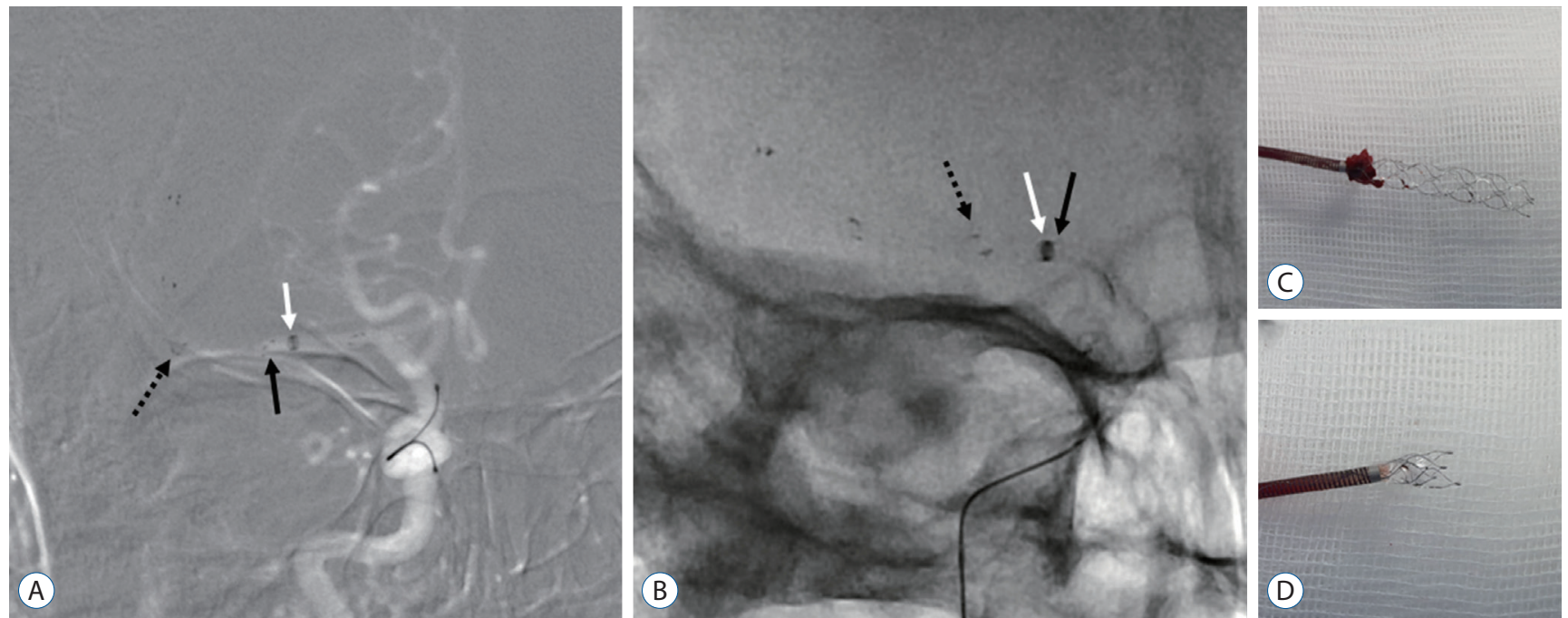

Fig. 2. Representative case of solumbra technique thrombectomy with a Solitaire platinum $4 \times 40 \mathrm{~mm}$ stent retriever. A : Roadmap image shows the location of the devices, before their retrieval (black arrow : the proximal end of the working length of the stent; black dotted arrow : mid-portion marker of the stent; white arrow : distal tip of the aspiration catheter). B : By a weak pull of the Solitaire platinum $4 \times 40 \mathrm{~mm}$ stent retriever, the distal tip of aspiration catheter (white arrow) should be placed just proximal to the thrombus and between the two markers (black and black dotted arrows) of the Solitaire platinum $4 \times 40 \mathrm{~mm}$ stent. C : After retrieval of the Solumbra technique devices, the thrombus was captured by the aspiration catheter and stent retriever. D : Image of the solumbra technique system after retrieval, in which the tip of the aspiration catheter was located distally beyond the midportion marker of the stent retriever. 
short stent retrievers. Furthermore, the multivariate analysis in our study showed that stent retrievers with longer length and radiopacity improved the first-pass effect in MT with Solumbra technique. These findings revealed the effectiveness of Solitaire Platinum $4 \times 40 \mathrm{~mm}$ stent retrievers compared to other $4 \mathrm{~mm}$ Solitaire stent retrievers, especially in MT with the Solumbra technique.

Longer stent retrievers have theoretical advantages because of the larger interaction area between the device and the thrombus, with lower chances of missing the target site than their shorter counterparts. In addition, the radiopaque characteristics of the device allow the interventionalists to view the entire stent, and confirm its optimal location and adequate vessel-wall apposition of the stent. Based on these characteristics, the usefulness of the Solitaire Platinum $4 \times 40 \mathrm{~mm}$ stent retriever and its technical considerations during the Solumbra technique thrombectomy was shown in (Fig. 2). Under roadmap guidance, the microcatheter was navigated distal to the occlusion site, and the Solitaire Platinum $4 \times 40 \mathrm{~mm}$ stent retriever was deployed to cover the distal and proximal ends of the occlusion. The aspiration catheter was navigated close to the clot, and the microcatheter was removed to increase the aspiration flow (Fig. 2A) ${ }^{26)}$. Next, the stent retriever was gently pulled with weak force and the distal tip of the aspiration catheter was moved to the distal lesion as close to the occlusion site as possible to contact the thrombus. At this time, the distal tip of the aspiration catheter should be placed just proximal to the site of the thrombus, between the two markers (mid-portion of the marker and the proximal end of the working length marker) of the Solitaire platinum $4 \times 40 \mathrm{~mm}$ stent retriever (Fig. 2B). After waiting several minutes to enable stent-clot integration, retrieval of the whole Solumbra system was performed for clot retrieval, with simultaneous continuous suction at the aspiration catheter and dual aspiration through the BGC. When the distal tip of the aspiration catheter was adequately positioned between the mid-portion marker and the proximal end of the working length marker without crossing the mid-portion marker, the thrombus could be retrieved as a single mass (Fig. 2C). However, frequent failures associated with thrombus retrieval occurred when the distal tip of the aspiration catheter was located more distally, beyond the mid-portion of the stent, and re-captured more than half of the stent retriever (Fig. 2D).

In the thrombectomy procedures using the Solumbra tech- nique, the aspiration catheter should re-capture less than half or one-third of the stent retriever to ensure an adequate stent retriever capture area to fully integrate with the clot. In addition, during the Solumbra system retrieval, the aspiration catheter is moved further distally depending on its tension, and the stent retriever is captured further by the aspiration catheter. In addition to the advantage of a long stent, the radiopacity of the Solitaire Platinum $4 \times 40 \mathrm{~mm}$ stent retriever with its markers $10 \mathrm{~mm}$ apart facilitate the correct positioning of the aspiration catheter and adjust the adequate capture range of the stent retrievers, especially during Solumbra technique thrombectomy. Therefore, a long and radiopaque stent retriever such as the Solitaire Platinum $4 \times 40 \mathrm{~mm}$ stent retriever, is preferred for MT by Solumbra technique.

The major limitations of this study were its relatively small sample size, and the retrospective non-blinded format. Since thrombectomy in the $4 \times 20 \mathrm{~mm}$ Solitaire stent retriever group was performed earlier than in the $4 \times 40 \mathrm{~mm}$ Solitaire Platinum stent retriever group, it may be assumed that the learning curve affected the outcome. However, all thrombectomy procedures in this study were performed by neuro-interventionalists with several years of experience. Therefore, the learning curve would not have a significant influence on the outcome. Furthermore, the baseline characteristics in the two groups were well balanced and there were no statistically significant differences. The disadvantages of longer stent retrievers include vessel damage or larger interface area with the vessel and consequently more friction. However, in our study, there were no significant differences in hemorrhage and dissection between the two groups. In addition, our study did not include the data associated with Solitaire FR $4 \times 40 \mathrm{~mm}$ retriever, which is a non-radiopaque and long Solitaire stent retriever. Other potential unmeasured confounding variables were not controlled for, although every effort was made to adjust for the possibility of spurious results.

\section{CONCLUSION}

In this study, the use of the Solitaire Platinum $4 \times 40 \mathrm{~mm}$ stent retriever for Solumbra technique thrombectomy in patients with LAO was highly effective, without increased periprocedural complications, compared with prior versions of the Solitaire FR $4 \times 20 \mathrm{~mm}$ stent and the Solitaire Platinum $4 \times$ 
$20 \mathrm{~mm}$ stent. The radiopacity and long length of the Solitaire Platinum $4 \times 40 \mathrm{~mm}$ stent retriever may contribute to more achievement of first-pass reperfusion and first-pass complete reperfusion, especially with Solumbra technique thrombectomy. Future prospective multicenter and in vitro studies are needed to corroborate our findings.

\section{CONFLICTS OF INTEREST}

No potential conflict of interest relevant to this article was reported.

\section{INFORMED CONSENT}

This type of study does not require informed consent.

\section{AUTHOR CONTRIBUTIONS}

\author{
Conceptualization : HJY, JHS \\ Data curation : HJY \\ Formal analysis : HJY \\ Methodology : HJY \\ Project administration : HJY, JHS \\ Visualization : HJY \\ Writing - original draft : HJY \\ Writing - review \& editing: HJY, JHS, DHL, SYS
}

\section{ORCID}

$\begin{array}{ll}\text { Ho Jun Yi } & \text { https://orcid.org/0000-0003-3061-0689 } \\ \text { Jae Hoon Sung } & \text { https://orcid.org/0000-0003-3738-6413 } \\ \text { Dong Hoon Lee } & \text { https://orcid.org/0000-0002-3796-8707 } \\ \text { Seung Yoon Song } & \text { https://orcid.org/0000-0002-6120-2795 }\end{array}$

\section{References}

1. Amarenco P, Bogousslavsky J, Caplan LR, Donnan GA, Hennerici MG : Classification of stroke subtypes. Cerebrovasc Dis 27 : 493-501, 2009

2. Berkhemer $O A$, Fransen $P S$, Beumer $D$, van den Berg LA, Lingsma HF, Yoo $A J$, et al. : A randomized trial of intraarterial treatment for acute ischemic stroke. N Engl J Med 372 : 11-20, 2015

3. Bourcier R, Saleme S, Labreuche J, Mazighi M, Fahed R, Blanc R, et al. : More than three passes of stent retriever is an independent predictor of parenchymal hematoma in acute ischemic stroke. J Neurointerv Surg $11: 625-629,2019$

4. Bracard S, Ducrocq X, Mas JL, Soudant M, Oppenheim C, Moulin T, et al. : Mechanical thrombectomy after intravenous alteplase versus alteplase alone after stroke (THRACE): a randomised controlled trial. Lancet Neurol 15 : 1138-1147, 2016

5. Campbell BC, Mitchell PJ, Kleinig TJ, Dewey HM, Churilov L, Yassi N, et al. : Endovascular therapy for ischemic stroke with perfusion-imaging selection. N Engl J Med 372 : 1009-1018, 2015

6. Dargazanli C, Consoli A, Barral M, Labreuche J, Redjem H, Ciccio G, et al. : Impact of modified $\mathrm{TICl} 3$ versus modified $\mathrm{TICl} 2 \mathrm{~b}$ reperfusion score to predict good outcome following endovascular therapy. AJNR Am J Neuroradiol 38 : 90-96, 2017

7. Dargazanli C, Fahed R, Blanc R, Gory B, Labreuche J, Duhamel A, et al. : Modified thrombolysis in cerebral infarction 2C/thrombolysis in cerebral infarction 3 reperfusion should be the aim of mechanical thrombectomy: insights from the ASTER trial (contact aspiration versus stent retriever for successful revascularization). Stroke 49 : 1189-1196, 2018

8. Deshaies EM : Tri-axial system using the Solitaire-FR and Penumbra Aspiration Microcatheter for acute mechanical thrombectomy. J Clin Neurosci 20 : 1303-1305, 2013

9. Goyal M, Demchuk AM, Menon BK, Eesa M, Rempel JL, Thornton J, et al. : Randomized assessment of rapid endovascular treatment of ischemic stroke. N Engl J Med 372 : 1019-1030, 2015

10. Goyal M, Menon BK, van Zwam WH, Dippel DW, Mitchell PJ, Demchuk $A M$, et al. : Endovascular thrombectomy after large-vessel ischaemic stroke: a meta-analysis of individual patient data from five randomised trials. Lancet 387 : 1723-1731, 2016

11. Hacke W, Kaste M, Bluhmki E, Brozman M, Dávalos A, Guidetti D, et al. : Thrombolysis with alteplase 3 to 4.5 hours after acute ischemic stroke.

N Engl J Med 359 : 1317-1329, 2008

12. Haussen DC, Al-Bayati AR, Grossberg JA, Bouslama M, Barreira C, Bianchi $N$, et al. : Longer stent retrievers enhance thrombectomy performance in acute stroke. J Neurointerv Surg $11:$ 6-8, 2019

13. Haussen DC, Lima A, Nogueira RG : The Trevo XP $3 \times 20 \mathrm{~mm}$ retriever ('Baby Trevo') for the treatment of distal intracranial occlusions. J Neurointerv Surg $8:$ 295-299, 2016

14. Hesse AC, Behme D, Kemmling A, Zapf A, Große Hokamp N, Frischmuth I, et al. : Comparing different thrombectomy techniques in five largevolume centers: a 'real world' observational study. J Neurointerv Surg $10: 525-529,2018$

15. Hopf-Jensen S, Preiß M, Marques L, Lehrke S, Schattschneider J, Stolze $H$, et al. : Impact and effectiveness of dual aspiration technique in stentassisted mechanical thrombectomy: recent improvements in acute stroke management. Cardiovasc Intervent Radiol 39 : 1620-1628, 2016

16. Humphries W, Hoit D, Doss VT, Elijovich L, Frei D, Loy D, et al. : Distal aspiration with retrievable stent assisted thrombectomy for the treatment of acute ischemic stroke. J Neurointerv Surg 7 : 90-94, 2015 
17. Jovin TG, Chamorro A, Cobo E, de Miquel MA, Molina CA, Rovira A, et al. : Thrombectomy within 8 hours after symptom onset in ischemic stroke. N Engl J Med 372 : 2296-2306, 2015

18. Kabbasch C, Mpotsaris A, Chang DH, Hiß S, Dorn F, Behme D, et al. : Mechanical thrombectomy with the Trevo ProVue device in ischemic stroke patients: does improved visibility translate into a clinical benefit? J Neurointerv Surg 8 : 778-782, 2016

19. Kaesmacher J, Maegerlein C, Zibold F, Wunderlich S, Zimmer C, Friedrich $B$ : Improving $\mathrm{mTICI} 2 \mathrm{~b}$ reperfusion to $\mathrm{mTICI} 2 \mathrm{c} / 3$ reperfusions: a retrospective observational study assessing technical feasibility, safety and clinical efficacy. Eur Radiol 28 : 274-282, 2018

20. Kang DH, Kim YW, Hwang YH, Park J, Hwang JH, Kim YS : Switching strategy for mechanical thrombectomy of acute large vessel occlusion in the anterior circulation. Stroke 44 : 3577-3579, 2013

21. Maegerlein C, Berndt MT, Mönch S, Kreiser K, Boeckh-Behrens T, Lehm $M$, et al. : Further development of combined techniques using stent retrievers, aspiration catheters and BGC : the PROTECTPLUS technique. Clin Neuroradiol 30 : 59-65, 2020

22. Maegerlein C, Mönch S, Boeckh-Behrens T, Lehm M, Hedderich DM, Berndt MT, et al. : PROTECT: PRoximal balloon Occlusion TogEther with direCt Thrombus aspiration during stent retriever thrombectomy - evaluation of a double embolic protection approach in endovascular stroke treatment. J Neurointerv Surg $10: 751-755,2018$

23. Maus V, Behme D, Kabbasch C, Borggrefe J, Tsogkas I, Nikoubashman 0 , et al. : Maximizing first-pass complete reperfusion with SAVE. Clin Neuroradiol 28 : 327-338, 2018

24. Maus V, Brehm A, Tsogkas I, Henkel S, Psychogios MN : Stent retriever placement in embolectomy: the choice of the post-bifurcational trunk influences the first-pass reperfusion result in M1 occlusions. J Neurointerv Surg $11: 237-240,2019$

25. Mizokami T, Uwatoko T, Matsumoto K, Ooya Y, Hashimoto G, Koguchi M, et al. : Aspiration Catheter Reach to Thrombus (ART) sign in combined technique for mechanical thrombectomy: impact for first-pass complete reperfusion. J Stroke Cerebrovasc Dis 28 : 104301, 2019

26. Nikoubashman O, Alt JP, Nikoubashman A, Büsen M, Heringer S, Brockmann $C$, et al. : Optimizing endovascular stroke treatment: removing the microcatheter before clot retrieval with stent-retrievers increases aspiration flow. J Neurointerv Surg 9 : 459-462, 2017

27. Pérez MA, Miloslavski $E$, Fischer $S$, Bäzner $H$, Henkes $H$ : Intracranial thrombectomy using the Solitaire stent: a historical vignette. J Neurointerv Surg 4 : e32, 2012

28. Pfaff J, Rohde S, Engelhorn T, Doerfler A, Bendszus M, Möhlenbruch MA : Mechanical thrombectomy using the new Solitaire ${ }^{\mathrm{TM}}$ Platinum stentretriever : reperfusion results, complication rates and early neurological outcom. Clin Neuroradiol 29 : 311-319, 2019

29. Saver JL, Goyal M, Bonafe A, Diener HC, Levy El, Pereira VM, et al. : Stent-retriever thrombectomy after intravenous t-PA vs. t-PA alone in stroke. N Engl J Med 372 : 2285-2295, 2015

30. Turk AS, Frei D, Fiorella D, Mocco J, Baxter B, Siddiqui A, et al. : ADAPT FAST study: a direct aspiration first pass technique for acute stroke thrombectomy. J Neurointerv Surg $6:$ 260-264, 2014

31. Yang D, Hao Y, Zi W, Wang $H$, Zheng $D$, Li H, et al. : Effect of retrievable stent size on endovascular treatment of acute ischemic stroke: a multicenter study. AJNR Am J Neuroradiol 38 : 1586-1593, 2017

32. Yi HJ, Lee DH, Sung JH : Clinical usefulness of waiting after stent deployment in mechanical thrombectomy: effect of the clot integration. World Neurosurg 119 : e87-e93, 2018

33. Yi HJ, Sung JH, Lee DH, Hong JT, Lee SW : Single-center experience of mechanical thrombectomy with the Trevo XP ProVue $6 \times 25 \mathrm{~mm}$ stent retriever in middle cerebral artery occlusion: comparison with Trevo XP ProVue $4 \times 20$ mm. World Neurosurg 107 : 649-656, 2017

34. Zaidat 00, Castonguay AC, Linfante I, Gupta R, Martin CO, Holloway $W E$, et al. : First pass effect: a new measure for stroke thrombectomy devices. Stroke 49 : 660-666, 2018 